\title{
Frailty, Mortality, and Health Related Quality of Life in Older Mexican Americans
}

\author{
Meredith C. Masel, PhD*, Glenn V. Ostir, PhD, and Kenneth J. Ottenbacher, PhD \\ The University Of Texas Medical Branch, Galveston
}

\begin{abstract}
OBJECTIVES-To determine the affect of health related quality of life on the relationship between frailty status and survival in Mexican American older adults.

DESIGN-Prospective analysis of participants in the Hispanic Established Populations for Epidemiologic Study of the Elderly.
\end{abstract}

PARTICIPANTS-1,008 Mexican American adults aged 74 to 101 interviewed between 2005 and 2006.

MEASUREMENTS-Information on patient demographics, health conditions, frailty status, health related quality of life, and survival was collected by trained interviewers.

RESULTS-Frailty was associated with a greater odds of death Odds Ratio (OR)=2.72 (95\% Confidence Interval $(\mathrm{CI})=1.5-5.1)$ over a period of 2-3 years. After adjusting for the physical component of health related quality of life, being frail (as opposed to prefrail or nonfrail) was no longer significantly associated with mortality. The mental health component of health related quality of life did not impact the relationship between frailty and mortality.

CONCLUSION-Older Mexican Americans identified as frail experienced decreased survival in this sample than their prefrail or nonfrail counterparts. Reduced survival in persons categorized as frail was attenuated by adjusting for the physical component of health related quality of life.

\section{MeSH Key Words}

Prevention; Death; Hispanic American

Frailty in older adults has been identified as a public health issue that may lead to premature death $^{1,2}$. The exact mechanisms whereby frailty influences mortality have not been thoroughly outlined, but presumably there are several pathways ${ }^{2}$. Because physical frailty is also strongly associated with poor health related quality of life ${ }^{3}$ it is plausible that health related quality of life may affect the relationship between frailty and mortality in older adults.

\footnotetext{
*Corresponding Author 301 University Blvd, Galveston, TX 77555-1137, (409) 772-9554, mcmasel@utmb.edu.

Dr. Ottenbacher is the Principal Investigator of the frailty substudy of the Hispanic EPESE.

Dr. Ostir has no conflict to report

Dr. Masel has no conflict to report.

Author Contributions

Dr. Masel performed the data analysis and prepared the manuscript. Dr. Ostir assisted with the interpretation of data and preparation of the manuscript. Dr. Ottenbacher designed the study used for the analysis, and assisted with the interpretation of data and preparation of the manuscript.
} 
Reduced health related quality of life, a person's perception of their physical and mental health, ${ }^{4}$ is associated with impairments from many major illnesses including arthritis, chronic lung disease, and heart disease ${ }^{5}$. In addition, among older adults, the consequences of poor health related quality of life include mortality 6,7 . Tsai, Chi, Lee, and Chou (2007) examined the influence of quality of life on death in older, community-dwelling adults ${ }^{7}$. They found that lower physical and mental health related quality of life ratings were significant independent predictors of mortality ${ }^{2}$.

Studies that have examined the relationship between self-rated health on mortality have been limited by their exclusion of relevant control variables and/or exclusion of measures that reflect a narrow variety of self-rated health constructs (e.g. global self-rated health) ${ }^{8,9}$. Furthermore, previous studies have examined restricted samples (e.g. hospital inpatients) so their results are difficult to generalize to other populations ${ }^{8}$.

The purpose of this study was to better understand the influences of health related quality of life on the relationship between frailty and mortality in older adults. We hypothesized that positive health related quality of life would mediate (or intervene in) the relationship between frailty status and mortality in Mexican American older adults. If adjusting for health related can help to explain the relationship between frailty status and decreased survival, a point of intervention for improving health related quality of life may be identified.

\section{Methods}

\section{Subjects}

Data are from the Hispanic Established Population for the Epidemiologic Study of the Elderly (EPESE). The Hispanic EPESE is a population based study of community-dwelling older Mexican Americans living in Texas, New Mexico, Colorado, Arizona, and California. Area probability sampling procedures identified participants through the selection of counties and households within identified census tracts. The sampling procedure allowed for data generalizable to approximately 500,000 older Mexican Americans living in the southwest beginning in the early 1990's and has been described in detail elsewhere ${ }^{10}$.

The original Hispanic EPESE was comprised of 3,050 participants who were interviewed in 1992 and continue to be followed. Data are collected at two-three year intervals from surviving members of the cohort. Information on variables, protocol, and data files from the Hispanic EPESE are available from the National Archive of Computerized Data on Aging ${ }^{11}$.

In 2006-2007, hereafter referred to as "baseline," 1,013 community-dwelling Mexican American participants, ages 74 years and older, were selected from the original sample to be included in a sub-study of frailty. Interviews were conducted in the participants' homes in English or Spanish by trained assessors. Verification phone calls were used to validate 15 percent of each interviewer's assessments. Vital status was collected during a follow up period from 2008 to 2009. Mortality was assessed by proxy with family or friends and verified from the Social Security Death Index. The study was approved by the University's Institutional Review Board on human protection and research ethics.

For the current study, several inclusion criteria were employed including 1) the ability to respond to questions or tasks essential to the frailty measure ${ }^{12}$ and 2) the presence of a standardized evaluation of health related quality of life $^{13}$. Information was not obtained via proxy respondents due to the performance based nature of the frailty measures (see description below). A total of 1008 participants met the inclusion criteria. 
The current analyses include evaluation of the relationships of frailty status and health related quality of life ratings at baseline (2006/2007) with mortality status at follow up (2008/2009). By the follow up period, 176 respondents were confirmed to have died, 35 participants were lost to follow-up, and 801 participants were alive. Of those lost to follow up, there were no differences in frailty scores from those who were either alive or dead by the second wave.

\section{Measures}

Health Related Quality of Life-Using the Medical Outcomes Study (MOS) Short Form -36 (SF-36) $^{13}$, we evaluated health related quality of life (HRQOL). The SF-36 measures physical functioning, daily activity limitations, bodily pain, general health, vitality, social functioning, and mental health in the form of eight subscales. Subscales have a range of 0 100 , with higher scores signifying a more positive evaluation. The physical subscales measuring physical problems, pain, and self-rated health, comprise a composite physical component scale (PCS) ranging from $0-100{ }^{9}$. The mental subscales, measuring daily functioning in relation to psychological issues and vitality, comprise a mental component scale (MCS) also ranging from 0-100 with 100 indicating no difficulties or impairments ${ }^{14}$. The SF-36 has been previously validated in older Mexican Americans ${ }^{15}$.

Frailty-We examined frailty using a slightly modified version of the frailty measure developed by Fried and colleagues ${ }^{11}$ based on walking speed, grip strength, (unintentional) weight loss, exhaustion, and physical activity. In our measure, the modification was using the Physical Activity Scale for the Elderly (PASE) ${ }^{16}$ instead of the Minnesota Leisure Activity Questionnaire ${ }^{17}$. The frailty measure has been previously described ${ }^{1-3}$.

Participants received one point each for 1) scoring in the bottom quartile for hand grip strength (adjusted for gender and body mass index (BMI)), 2) having greater than or equal to ten pounds of unintended weight loss in the prior year, 3) scoring in the bottom quintile for walking speed (adjusted for gender and height), 4) reporting at least a moderate amount of time feeling exhausted during the previous week (as determined by responses to the Centers for Epidemiologic Study-Depression scale ${ }^{18}$ (CES-D)), or 5) scoring in the bottom quintile for physical activity (adjusted for gender) as measured by the Physical Activity Scale for the Elderly ${ }^{16}$. The Centers for Epidemiologic Study Depression scale and the Physical Activity Scale for the Elderly have been previously validated and are appropriate for use in studies of community-dwelling adults ${ }^{16,18}$. Based on previous research, a score of zero was considered to mean that a participant was not frail. Participants with one to two symptoms were considered pre-frail, and those with three or more symptoms were considered to be frail ${ }^{1}$.

Socioeconomic Status and Health-We adjusted for several sociodemographic and health-related variables known to be related to frailty, mortality, and/or health related quality of life in this population ${ }^{1-3}$ including age, sex (male $=0$, female $=1$ ), and marital status ( married $=1$, not married $=0$ ). Education level was measured by number of years of schooling ranging $0-20$ years. Financial strain was measured by asking participants how much difficulty they had paying monthly bills (little to no trouble $=0$ or some trouble to a great deal of trouble $=1$ ).

Health conditions were also measured by participants' responses (no=0, yes=1) to selfreported doctor diagnosis of arthritis, heart attack, stroke, hypertension, cancer, diabetes, hip fracture, or other fractures. Comorbidities were combined to create a comorbidity index (or summary score) with the exception of arthritis. Arthritis was independently included in the analyses because preliminary analyses indicated it had a strong relationship with frailty and 
certain subscales of the health related quality of life measure. Finally, body mass index (BMI) was calculated by dividing individuals' weight in kilograms by height in meters squared. As defined by the World Health Organization ${ }^{19}$, BMI categories (underweight, normal weight, overweight, or obese) were used in the analyses.

\section{Analysis}

Baseline descriptive statistics were presented by mortality status and differences between groups were assessed via Analyses of Variance (ANOVA), t-tests and chi-square tests for independence. Logistic regression models calculated the odds of death in the second wave using a multivariable approach. Frailty was first entered into the models followed by sociodemographic and health-related variables. In order to identify potential issues with collinearity and/or overly influential variables, regression diagnostics included tests for associations between the predictor and outcome variables and tests for normality of residuals with kernel density plots. Model fit statistics were examined to assure goodness of fit (results not presented). Statistical analyses were conducted with Statistical Analysis Software (SAS) version 9.1 [SAS Institute, Inc., Cary, $\mathrm{NC}^{20}$.

\section{Results}

Table 1 represents the baseline descriptive statistics of the participants in the study by their follow up mortality status. At follow up, frail compared to non-frail or pre-frail participants were more likely to die. In addition, those who died were significantly more likely to have been frail, older, male, and have more chronic illnesses. Furthermore, those who died had significantly lower mean physical $(31.5 \pm 12.1)$ and mean mental $(51.8 \pm 12.6)$ component scores than those who were alive ( $38.1 \pm 11.8$ and $54.4 \pm 10.5$, respectively).

Table 2 presents the results of the logistic regression analysis of the effects of health related quality of life on the relationship between frailty and mortality. Being frail at baseline was associated with a 2.7 greater odds of death in the second wave compared with non-frail or pre-frail (column 1). In the next model, each additional point on the physical component scale was associated with a $4 \%$ decrease in odds of death by wave two (model 2). In addition, when adjusted for in the variables in the models, the physical component scale attenuated the relationship between frailty and death so that being frail was no longer significantly associated with dying by wave two. In fact, the odds of death decreased by $40 \%$ from 2.7 to 1.6. In the final model, when adjusting only for the mental component scale, there were no apparent effects on odds of death.

To further clarify these findings, several analyses examined the relationship between frailty status and mortality among the subscales of the health-related quality of life measure (Table 3). Three of the SF-36 subscales (role emotional, mental health, and role physical) were not associated with mortality in multivariable models. The remaining subscales (bodily pain, social functioning, physical functioning, vitality, and general health) were associated with mortality status in similar ways as the mental and physical composite scales. The physical function subscale had the same mediating effect on the outcome as did the PCS composite scale indicating that self-rated physical functioning may make a larger contribution to our findings.

In addition, we stratified our analyses by gender because research has shown gender differences in mortality (results not shown). There were no differences in the findings. Furthermore, in our multivariable models, we explored one model with both the mental component scale and the physical component scale as predictor variables. There were no significant differences in our findings. 


\section{Discussion}

The purpose of this research was to examine the effects of a person's health related quality of life on the relationship between frailty status and mortality. Our hypothesis was that, when accounting for self-rated health status using questions from the SF- $36^{13}$, the effect of frailty status on mortality would decrease. We found partial support for our hypothesis in a sample of older Mexican Americans. Higher scores on the physical component scale of the SF-36 at baseline were significantly associated with lower odds of death at follow up and also substantially attenuated the relationship between being frail compared to not frail or pre-frail at baseline and having increased odds of death. The same effects were not found for the mental component scale.

It has been previously shown that frailty and health-related quality of life are associated with increased mortality 2,7 . The current analyses suggest that health related quality of life might intervene in the relationship between frailty and decreased survival. Potential explanations for this finding include 1) the differences in the way people adapt to frailty ${ }^{21}$, and 2) the effect that a sense of control despite physical limitations has on health related quality of life responses ${ }^{21}$. Regarding the first explanation, positive adaptive or coping styles are associated with decreased mortality in older adults with disabilities ${ }^{22}$. Thus, those who accept the limitations of physical frailty and find alternative ways to maintain their lifestyle (through the use of positive emotions or simple assistive devices) may prolong their lives.

Another possible explanation for our findings is that positive health related quality of life may be a side effect of a person's sense of control ${ }^{21}$ or sense of anticipated support from others despite their frail status. Decreased control over one's life/health can have an effect on mortality ${ }^{23}$. Considering the health related quality of life subscale is comprised of a person's opinion about if their health limits them from physical activities such as walking, running, climbing, daily tasks, and lifting it may seem as redundant to the frailty measure. On the contrary, we believe the self-rated nature of the SF-36 measure provides a deeper insight to the limitations that physical frailty may or may not pose. In other words, whether one thinks they are limited is different from whether or not they actually experience limitations.

This study has limitations. It is possible that, although a participant was categorized as frail, simultaneous good physical health as measured by the SF-36 may be an indicator that they have been misclassified based on our frailty criteria. Further, the inclusion of self-reported data may introduce bias that we are unable to control. For example, our measure of physical activity does not rely on participants' fitness level or ability, rather their opinion of their frequency of activity. In addition, due to a lack of available measures, we are unable to test our proposed explanations for the relationships we found. Future research should focus on exploring the circumstances that influence the way people adapt to frailty.

Because improved physical health related quality of life may prevent premature death in frail older adults, effective management of frailty offers unique opportunities, both to reduce its social burden and mitigate its relationship with mortality. Future research should examine if health related quality of life is associated with not only increased survival in frail elders, but also compression of morbidity.

\section{Acknowledgments}

Sponsor's Role

None. 
Dr. Masel is supported by DOE/NIDRR H133P040003. Dr. Ostir is supported by K01-HD046682. Dr. Ottenbacher is supported by H133G080163.

\section{Reference List}

1. Ottenbacher KJ, Graham JE, Al Snih S, et al. Mexican Americans and frailty: Findings from the Hispanic established populations epidemiologic studies of the elderly. Am J of Public Health. 2009; 99:673-679. [PubMed: 19197079]

2. Graham JE, Snih SA, Berges IM, Ray LA, Markides KS, Ottenbacher KJ. Frailty and 10-year mortality in community-living Mexican American older adults. Gerontol. 2009; 55:644-651.

3. Masel M, Graham J, Reistetter T, Markides K, Ottenbacher K. Frailty and health related quality of life in older Mexican Americans. Health Qual Life Outcomes. 2009; 7:70. [PubMed: 19627598]

4. Centers for Disease Control and Prevention. Health related quality of life. 2009 [(Accessed 4/29/2010)]. http://www.cdc.gov/hrqol/

5. Alonso J, Ferrer M, Gandek B, et al. Health-related quality of life associated with chronic conditions in eight countries: Results from the international quality of life assessment (IQOLA) project. Qual Life Res. 2004; 13:283-298. [PubMed: 15085901]

6. Rumsfeld JS, MaWhinney S, McCarthy M Jr, et al. Health-related quality of life as a predictor of mortality following coronary artery bypass graft surgery. JAMA. 1999; 281:1298-1303. [PubMed: 10208145]

7. Tsai SY, Chi LY, Lee Ch, Chou P. Health-related quality of life as a predictor of mortality among community-dwelling older persons. Eur J Epidemiol. 2007; 22:19-26. [PubMed: 17216549]

8. Chochinov HM, Tataryn D, Clinch JJ, Dudgeon D. Will to live in the terminally ill. The Lancet. 1999; 354:816-819.

9. Idler EL, Benyamini Y. Self-rated health and mortality: A review of twenty-seven community studies. J Health Soc Beh. 1997; 38:21-37.

10. Markides, KS.; Stroup-Benham, CA.; Black, SA., et al. The health of Mexican American elderly: Selected findings from the Hispanic EPESE. New York: Springer; 1999.

11. Inter-University Consortium for Political and Social Research. National archive of computerized data on aging. 2009. http://www.icpsr.umich.edu/NACDA/

12. Fried LP, Tangen CM, Walston J, et al. Frailty in older adults: Evidence for a phenotype. J Gerontol A Biol Sci Med Sci. 2001; 56:M146-M157. [PubMed: 11253156]

13. Ware JE Jr, Sherbourne CD. The MOS 36-item short-form health survey (sf-36): I. Conceptual framework and item selection. Med Care. 1992; 30:473-483. [PubMed: 1593914]

14. Ware, JE., Jr; Kosinski, M. Interpretation: Content and criterion-based. Lincoln, RI: QualityMetric Incorporated; 2001.

15. Peek MK, Ray L, Patel K, Stoebner-May D, Ottenbacher KJ. Reliability and validity of the sf-36 among older Mexican Americans. The Gerontologist. 2004; 44:418-425. [PubMed: 15197296]

16. Washburn RA, McAuley E, Katula J, Mihalko SL, Boileau RA. The physical activity scale for the elderly (PASE): Evidence for validity. J Clin Epidemiol. 1999; 52:643-651. [PubMed: 10391658]

17. Richardson M, Leon A, Jacobs D, et al. Comprehensive evaluation of the Minnesota leisure time physical activity questionnaire. J Clinical Epidemiol. 1994; 47:271-281. [PubMed: 8138837]

18. Radloff LS. The CES-D scale: A self-report depression scale for research in the general population. Appl Psychol Meas. 1977; 1:385-401.

19. World Health Organization. The international classification of adult underweight, overweight and obesity according to BMI. Global Database on Body Mass Index. 2010 [(Accessed 04/30/2010)]. http://www.who.int

20. SAS Institute Inc. SAS Software. Version 9.1.3. Cary, N.C: SAS Institute Inc; 2008.

21. Sprangers MAG, Schwartz CE. Integrating response shift into health-related quality of life research: A theoretical model. Soc Sci Med. 1999; 48:1507-1515. [PubMed: 10400253]

22. Bernard SL, Kincade JE, Konrad TR, et al. Predicting mortality from community surveys of older adults: The importance of self-rated functional ability. J Gerontol B: Psychol Sci Soc Sci. 1997; 52:S155-S163. [PubMed: 9158572] 
23. Menec VH, Chipperfield JG. The interactive effect of perceived control and functional status on health and mortality among young-old and old-old adults. J Gerontol B: Psychol Sci Soc Sci. 1997; 52:118-126. 


\section{Table 1}

Respondent sociodemographic and health characteristics from the frailty subsample of the Hispanic EPESE $(\mathrm{n}=1008)$

\begin{tabular}{|c|c|c|c|}
\hline \multirow[t]{2}{*}{ Variable } & \multirow[t]{2}{*}{ All Respondents at Baseline $(n=1008)$} & \multicolumn{2}{|c|}{ Baseline Values by Vital Status at follow-up } \\
\hline & & Alive $(n=801)$ & Dead $(n=176)$ \\
\hline \multicolumn{4}{|l|}{ Frailty } \\
\hline Not Frail \% & 26.1 & 88 & 12 \\
\hline Prefrail \% & 54.1 & 84 & 16 \\
\hline Frail \% & 19.8 & 68.7 & 31.3 \\
\hline PCS $^{*} \mu(\mathbf{s d})$ & $36.9(12.2)$ & $38.1(11.8)$ & $31.5(12.1)$ \\
\hline $\operatorname{MCS}^{\dagger} \mu(\mathbf{s d})$ & $54(10.9)$ & $54.4(10.5)$ & $51.8(12.6)$ \\
\hline Age $\mu($ sd) & $82.3(4.6)$ & $81.9(4.3)$ & $84(5.4)$ \\
\hline \multicolumn{4}{|l|}{ Sex } \\
\hline Male\% & 36.8 & 77.6 & 22.4 \\
\hline Female \% & 63.2 & 84.5 & 15.5 \\
\hline Grade $\mu(\mathrm{sd})$ & $5.1(3.9)$ & $5.1(3.9)$ & $5.3(3.6)$ \\
\hline \multicolumn{4}{|l|}{ Marital Status } \\
\hline Married \% & 59.33 & 81.9 & 18.1 \\
\hline Not Married \% & 40.67 & 82.1 & 17.9 \\
\hline \multicolumn{4}{|l|}{ Financial Strain } \\
\hline Financially Strained \% & 61.25 & 83.1 & 16.9 \\
\hline Not Strained \% & 38.75 & 81.1 & 18.9 \\
\hline \multicolumn{4}{|l|}{ Arthritis } \\
\hline With Arthritis \% & 63.19 & 82.4 & 17.6 \\
\hline Without Arthritis \% & 36.81 & 81.1 & 18.9 \\
\hline Chronic illnesses $\mu(\mathbf{s d})$ & $1.8(1.2)$ & $1.8(1.2)$ & $2.2(1.3)$ \\
\hline \multicolumn{4}{|l|}{ Smoking } \\
\hline Smoker \% & 5.9 & 82.5 & 17.5 \\
\hline Non-Smoker \% & 94.1 & 82 & 18 \\
\hline \multicolumn{4}{|l|}{ Body Mass Index ${ }^{\ddagger}$} \\
\hline Underweight \% & 1.33 & 75 & 25 \\
\hline Normal Weight \% & 32.93 & 81.8 & 18.2 \\
\hline Overweight $\%$ & 40.1 & 84.8 & 15.2 \\
\hline Obese \% & 25.64 & 88.6 & 11.4 \\
\hline \multicolumn{4}{|l|}{ * Physical Component Scale } \\
\hline Mental Component Scale & & & \\
\hline
\end{tabular}

$J$ Am Geriatr Soc. Author manuscript; available in PMC 2011 November 1. 


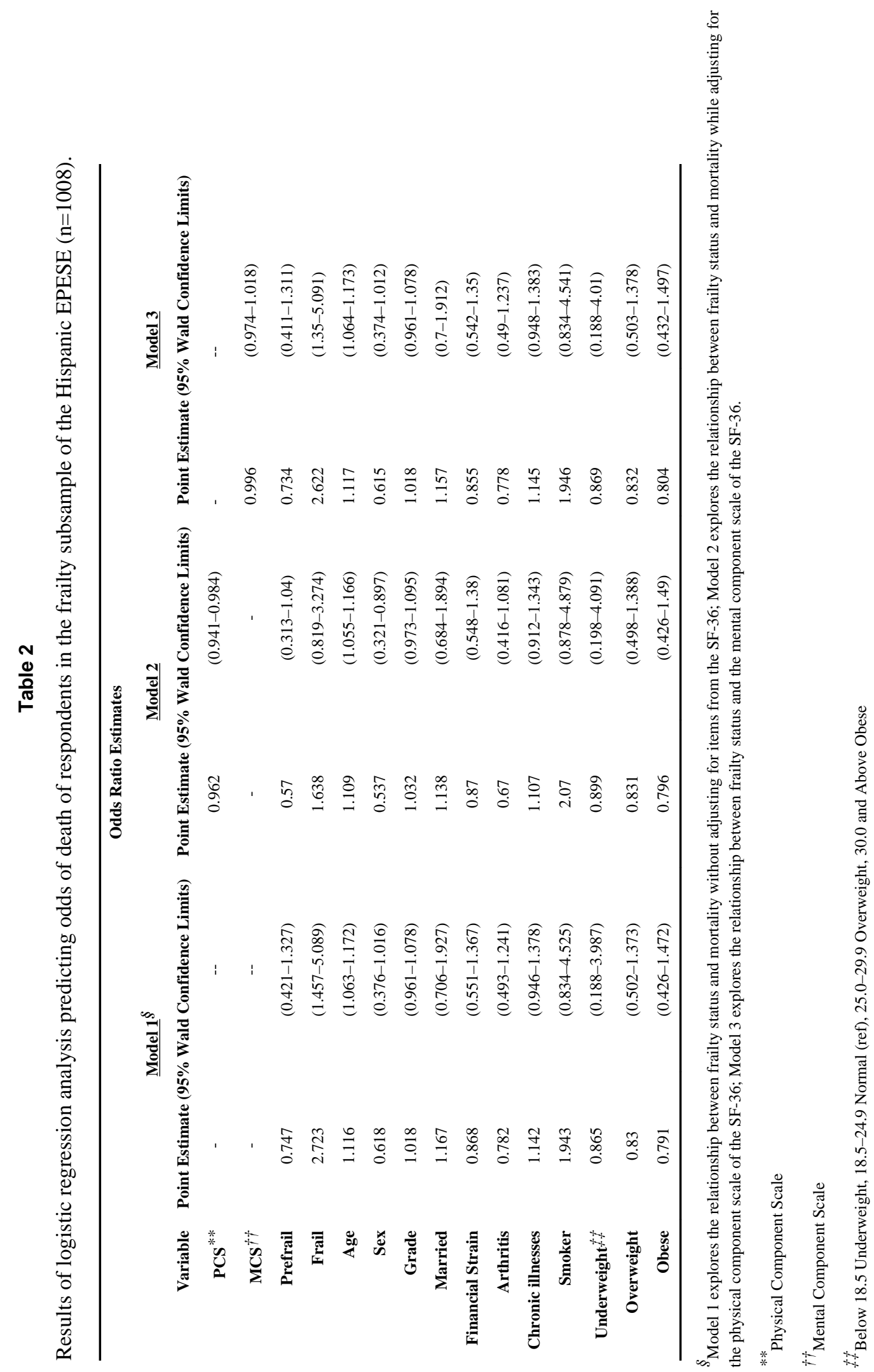


Table 3

Results of Logistic Regression Analysis predicting odds of death of respondents in the frailty subsample of the Hispanic EPESE ( $\mathrm{n}=1008)$ adjusting for subscales of the SF-36.

\begin{tabular}{|c|c|}
\hline & Odds Ratio Estimates* \\
\hline Variable & Point Estimate (95\% Wald Confidence Limits) \\
\hline Social Function & $0.988(0.98-0.996)$ \\
\hline Prefrail & $0.618(0.341-1.12)$ \\
\hline Frail & $1.73(0.86-3.5)$ \\
\hline Vitality & $0.99(0.98-0.998$ \\
\hline Prefrail & $0.65(0.36-1.17)$ \\
\hline Frail & $1.95(0.98-3.9)$ \\
\hline Role Emotional & $1.001(0.996-1.01)$ \\
\hline Prefrail & $0.76(0.43-1.36)$ \\
\hline Frail & $2.88(1.49-5.57)$ \\
\hline Mental Health & $0.99(0.98-1.01)$ \\
\hline Prefrail & $0.72(0.401-1.28)$ \\
\hline Frail & $2.45(1.28-4.7)$ \\
\hline Bodily Pain & $0.992(0.98-1.00)$ \\
\hline Prefrail & $0.68(0.38-1.22)$ \\
\hline Frail & $2.27(1.18-4.36)$ \\
\hline Role Physical & $0.99(0.99-1.002)$ \\
\hline Prefrail & $0.69(0.38-1.24)$ \\
\hline Frail & $2.35(1.2-4.58)$ \\
\hline Physical Function & $0.98(0.98-0.99)$ \\
\hline Prefrail & $0.56(0.3-1.01)$ \\
\hline Frail & $1.48(0.73-3.01)$ \\
\hline General Health & $0.99(0.98-0.99)$ \\
\hline Prefrail & $0.66(0.37-1.19)$ \\
\hline Frail & $2.03(1.04-3.99)$ \\
\hline
\end{tabular}

$J$ Am Geriatr Soc. Author manuscript; available in PMC 2011 November 1. 